\title{
Fermentation Tank Dissolve Oxygen Control System Based on MATLAB
}

\author{
Peiguang Wang, Daogeng Zhang ${ }^{a}$, Xiaoping Zong \\ School of Hebei, Hebei University, Baoding 071002, China \\ a1147139508@qq.com
}

Keywords: dissolve oxygen, fuzzy control, PID, Simulink.

\begin{abstract}
Dissolve oxygen of fermentation tank system is nonlinear, time varying system. The conventional PID controllers not usually applicable to the type of systems. So a new fuzzy adaptive PID controller is presented constructing the PID control system in Simulink environment, and using a fuzzy logic control toolbox in Matlab to design the fuzzy controller, the computer simulation of this adaptive fuzzy PID controller is realized. Using the Matlab fuzzy logic toolbox to design the fuzzy controller control, And in Simulink conventional PID controller and the adaptive fuzzy PID controller emulation, The simulation result, the adaptive fuzzy PID controller has fast response speed, control sensitivity and adapt to the advantages of strong performance.
\end{abstract}

\section{Introduction}

In the modern society, the biological technology is constantly developing, and the fermentation technology is paid more and more attention by people. Fermentation tank is the main production site of biological products. ${ }^{[1-2]}$ Dissolved oxygen in the process of fermentation is one of its main parameters.For fermentation tank of dissolved oxygen (DO) at different stage of the fermentation process should keep in a certain range, how to maintain stability of the fermentation reaction of dissolved oxygen (DO) is normal, that is an important link in the fermentation process. Therefore, the need to design the controller to ensure the stability of the dissolved oxygen (DO) normal. However, the traditional PID control method can not meet the requirements of the current control, in the production site, because the traditional PID parameters tuning method is complicated, its parameters will be the whole set, performance is not good, the whole qualitative difference between the operating conditions. Fuzzy reasoning method was adopted to realize self-tuning of PID parameters, not only keep the traditional principle of PID control system is simple, easy to use, the advantages of strong robustness, also has more flexibility, the qualitative, control accuracy is better, is one of the more advanced control system. The computer simulation of the fuzzy self tuning PID parameter control system with MATLAB is convenient and fast to realize accurate simulation results of many parameters and rules, which greatly improve the efficiency and accuracy of the design of the fuzzy self-tuning PID parameters control system. ${ }^{[3]}$

\section{Mathematical model of dissolved oxygen in fermentation tank}

In the aerobic microbial fermentation process, oxygen is essential for microbial growth and development of raw materials, if enough oxygen will suppress microbial growth and product generation, and therefore the fermentation process to maintain a certain concentration of dissolved oxygen. To find the relevant literature that dissolved oxygen characteristics of microbial fermentation for the open-loop transfer function of two order inertial link, the dissolved oxygen (DO) transfer function is

$$
\mathrm{G}(s)=\frac{K}{\left(T_{1} s+1\right)\left(T_{2} s+1\right)}
$$

Type: $K$ for the fermentation system of aseptic air flow ratio; $T_{1}$ and $T_{2}$ for the Inertia time constant of the fermentation system. 
According to the Microbial growth curve in biological fermentation process, Obtain the transfer function of microbial fermentation dissolved oxygen control model:

$$
G(s)=\frac{140}{100 s^{2}+99 s+1}
$$

\section{Design Adaptive Fuzzy PID Controller}

\subsection{Cprinciple of Adaptive Fuzzy PID Controller}

In the process of manual operation, the amount of information obtained is basically three: the error, the change of the error, the change of the error change (i.e., the rate of the change of the error). Generally speaking, people are the most sensitive to the error, followed by the change of the error, the least sensitive to the rate of error change. In theory, the higher the dimension of fuzzy controller, the more precise control. But the dimension is too high, the fuzzy control rules become too complex, and the control algorithm is very difficult. As a result, the adaptive fuzzy PID controller with error (e) and error change (ec) rate as input, can satisfy different time e and ec demand for PID parameters self-tuning. Using the fuzzy control rules to modify the PID parameters, constitute the adaptive fuzzy PID controller.

Fuzzy PID parameters self-tuning is to find the three parameters of PID and fuzzy relation between the e and ec, through continuous testing e and ec in the run, And the PID parameters of the correction $\left(\Delta K_{p}, \Delta K_{i}, \Delta K_{d}\right)$ for the output, In order to meet the different time deviation and the deviation change requirement for PID parameters setting, so that the controlled object has good static and dynamic characteristics. Finally get 3 parameters of PID controller, in the following equation, $K_{p}^{\prime}, K_{i}^{\prime}, K_{d}^{\prime}$ for the presetting value.

$$
\begin{aligned}
& K_{p}=K_{p}^{\prime}+\Delta K_{p} \\
& K_{i}=K_{i}^{\prime}+\Delta K_{i} \\
& K_{d}=K_{d}^{\prime}+\Delta K_{d}
\end{aligned}
$$

The principle of adaptive fuzzy PID controller is shown in Fig.1.

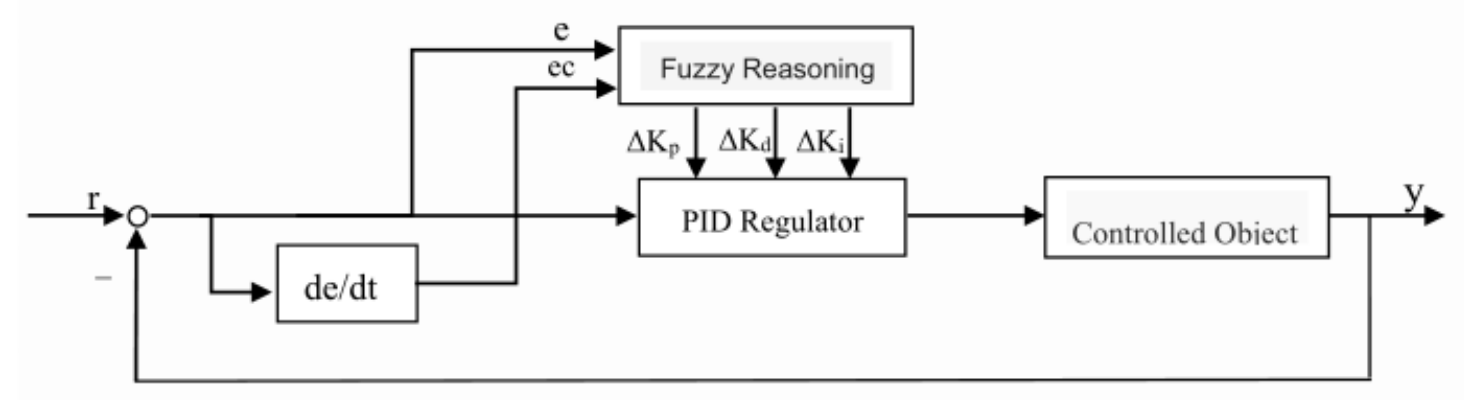

Fig. 1 The principle of adaptive fuzzy PID controller

After analysis, it can be concluded that the parameters of the control performance can be improved:

(1) When the error (e) is large, it is necessary to increase the value of $K_{p}$ to achieve the purpose of speed up the system's response speed; In order to prevent the differential over saturation caused by the moment of the error of the start, the control action is beyond the scope of the permit. Should select the smaller $K_{d}$; In addition, in order to avoid the system appear larger overshoot, limit of $K_{i}$, and take values of $K_{i}$ converge to zero.

(2) When the error (e) and error change (ec) rate is in the intermediate value, in order to reduce the overshoot of the system response and ensure a certain response speed, smaller $K_{p}$. In this case, the value of $K_{d}$ has a greater impact on the system, and the system can ensure the response speed, and has a smaller overshoot. The value of $K_{i}$ should be appropriate. 
(3) When the error(e) is smaller, in order to avoid shock, make the system has good steady-state performance, appropriately increase the value of $K_{p}$, reducing the value of $K_{i}$. The value of $K_{d}$ needs to be determined according to the variation of the error rate. When the error (e) rate is small, $K_{d}$ should take a few bigger; When the error rate is larger, $K_{d}$ should be smaller.

Determine the variable membership function: Upon request, the fuzzy controller is used to adjust the PID parameters using two input and three output form. The controller is based on error (e) and error change (ec) rate as input, three parameters of PID controller P, I, D correction $\Delta K_{p}, \Delta K_{i}, \Delta K_{d}$ as output. Fuzzy subset taken for the inputs and outputs\{NB,NM,NS,ZO,PS,PM,PB\}, The subset of elements representing the Negative Big, the Negative Middle, the Negative Small, the Zero, the Positive Small, the Positive Middle, the Positive Big. In the fuzzy logic toolbox membership function editor, Select e and ec as input, $\Delta K_{p}, \Delta K_{i}, \Delta K_{d}$ as output, their membership functions are gaussian model and triangular.

According to the PID parameters self-tuning control rules, in combination with the engineering design technical knowledge and dissolved oxygen regulation of experience, the establishment of fuzzy control rules:

1. If (e is $\mathrm{NB})$ then (Kp is $\mathrm{PB})(\mathrm{Ki}$ is $\mathrm{ZO})(\mathrm{Kd}$ is $\mathrm{PS})(1)$

2. If (e is NM) and (ec is NM) then (Kp is PS)(Ki is PS)(Kd is PS) (1)

3. If (e is $\mathrm{NM}$ ) and (ec is $\mathrm{PM}$ ) then ( $\mathrm{Kp}$ is $\mathrm{PS})(\mathrm{Ki}$ is $\mathrm{PS})(\mathrm{Kd}$ is $\mathrm{PS})(1)$

4. If (e is NS) and (ec is $\mathrm{NB})$ then $(\mathrm{Kp}$ is $\mathrm{PM})(\mathrm{Ki}$ is $\mathrm{PS})(\mathrm{Kd}$ is $\mathrm{PS})(1)$

5. If (e is NS) and (ec is NS) then (Kp is $\mathrm{PM})(\mathrm{Ki}$ is $\mathrm{PS})(\mathrm{Kd}$ is $\mathrm{PB})(1)$

6. If (e is NS) and (ec is PS) then (Kp is $\mathrm{PM})(\mathrm{Ki}$ is $\mathrm{PS})(\mathrm{Kd}$ is $\mathrm{PB})(1)$

7. If (e is NS) and (ec is $\mathrm{PB})$ then (Kp is $\mathrm{PM})(\mathrm{Ki}$ is $\mathrm{PS})(\mathrm{Kd}$ is $\mathrm{PS})(1)$

8. If (e is PS) and (ec is $\mathrm{NB})$ then (Kp is $\mathrm{PM})(\mathrm{Ki}$ is $\mathrm{PS})(\mathrm{Kd}$ is $\mathrm{PS})(1)$

9. If (e is PS) and (ec is NS) then (Kp is $\mathrm{PM})(\mathrm{Ki}$ is $\mathrm{PS})(\mathrm{Kd}$ is $\mathrm{PB})(1)$

10. If (e is $\mathrm{PS}$ ) and (ec is $\mathrm{PS})$ then $(\mathrm{Kp}$ is $\mathrm{PM})(\mathrm{Ki}$ is $\mathrm{PS})(\mathrm{Kd}$ is $\mathrm{PB})(1)$

11. If (e is PS) and (ec is $\mathrm{PB})$ then (Kp is $\mathrm{PM})(\mathrm{Ki}$ is $\mathrm{PS})(\mathrm{Kd}$ is $\mathrm{PS})(1)$

12. If (e is $\mathrm{PM})$ and (ec is NM) then (Kp is $\mathrm{PS})(\mathrm{Ki}$ is $\mathrm{PS})(\mathrm{Kd}$ is $\mathrm{PS})(1)$

13. If (e is $\mathrm{PM}$ ) and (ec is $\mathrm{PM})$ then (Kp is $\mathrm{PS})(\mathrm{Ki}$ is $\mathrm{PS})(\mathrm{Kd}$ is $\mathrm{PS})(1)$

14. If (e is $\mathrm{PB})$ then $(\mathrm{Kp}$ is $\mathrm{PB})(\mathrm{Ki}$ is $\mathrm{ZO})(\mathrm{Kd}$ is $\mathrm{PS})(1)$

\subsection{Design of adaptive fuzzy PID controller}

(1)In Simulink, the module of Fuzzy controller and PID controller is shown in Fig.2, Fig.3.

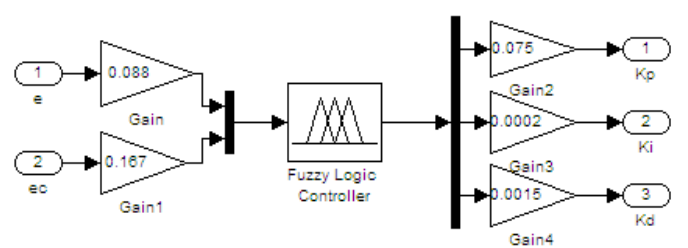

Fig.2 Fuzzy Controller

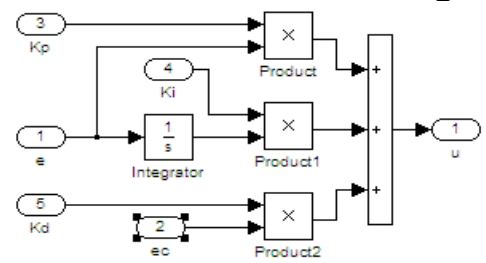

Fig.3 PID Controller

The two modules respectively packaging and connect them, as shown in Fig.4.

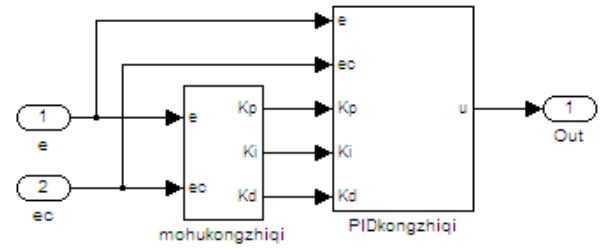

Fig4 Encapsulation of Fuzzy Controller and PID Controller 


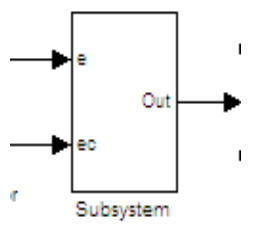

Fig5 the Adaptive Fuzzy PID Controller

(2) The fuzzy controller and PID controller respectively after packaged together constituted the composite controller, then the two packaging, packaging can be adaptive Fuzzy PID controller, as show in Fig.5.

\section{System Simulation}

In order to compare the control effect, Comparison between PID controller and adaptive fuzzy PID controller, to verify the correctness of the designed controller. The design of the fermentation tank dissolved oxygen (DO) control system as shown in Fig.6, the simulation results are shown in Fig.7.

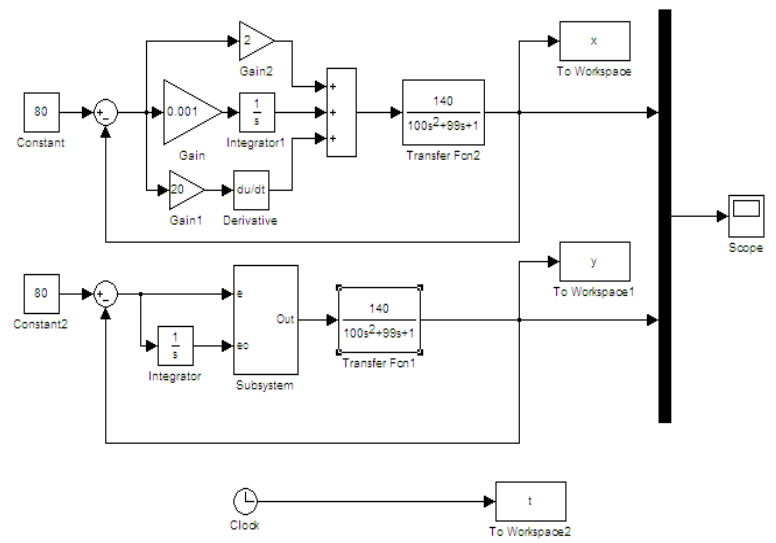

Fig. 6 Comparison of dissolved oxygen in the fermenter two control systems

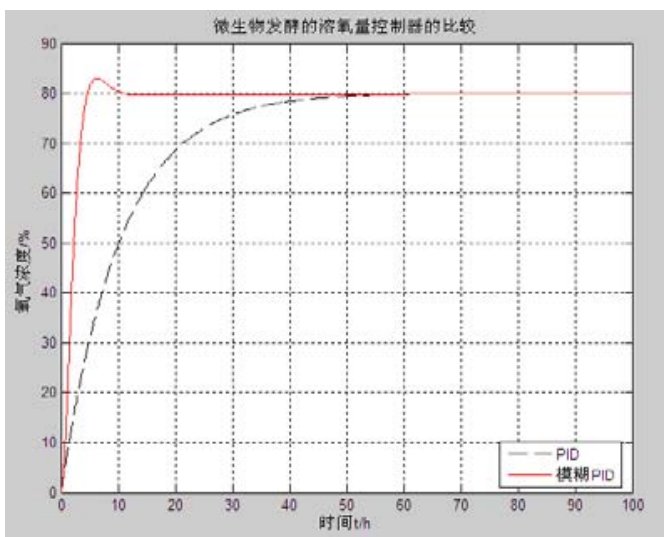

Fig.7 Simulation Results

From the simulation results, the designed adaptive fuzzy PID controller has the advantages of flexible control, fast response, and so on. At the same time can be seen, the adaptive fuzzy PID controller is shorter than the conventional PID controller's rise time and regulation time. And the steady state error is also small, it has better robustness, Improve the static and dynamic performance index of control system. But, the overshoot of the fuzzy PID controller is larger.

\section{Summary}

Using Simulink to dissolve oxygen of conventional PID controller and adaptive fuzzy PID controller for the simulation and comparison analysis, the adaptive fuzzy PID controller to control system has higher stability and reliability, more to meet the requirements of the microbial fermentation of oxygen concentration. The adaptive fuzzy PID controller not only makes the 
dissolved oxygen value remained stable, to ensure the normal life of microorganisms, but also to ensure the quality and quantity of the microorganism metabolites, At the same time reduce the waste of resources, Improve the production efficiency, energy conservation, environmental protection, has better application prospect.

\section{References}

[1]Xiong Ruichang,zhou Zekui, Wang Qiang. With functions of automatic calibration of fermentation tank multipoint temperature acquisition system [J]. Automation instrument,2005, 26 (6):38-40.

[2] Xiong Weili,Xu Baoguo,Xiao Yingwang. Fuzzy - PI fermentation temperature control system based on PLC [J]. Computer engineering,2005,31(9):207-209.

[3] Shi Li.Intelligent control theory and application [M]. Beijing: Tsinghua University Press,2009.

[4] Lai Shouhong. Microcomputer control technology [M]. Beijing: Mechanical Industry Publishing House, 2003:90-106.

[5]Zhang Jiangren, Wang Li. The fuzzy control system based on MATLAB simulation [J]. Automation and instrumentation,2003,(1):5-8

[6]Chang Manpo,Hu Pengfei . Fuzzy PID controller design based on MATLAB and simulation study [J]. Journal of the Locomotive Electric Transmission,2002,(5):34-36.

[7]Tao Yonghua . New PID control and its application [M]. Beijing: mechanical industry press,2002.

[8]Liu Jinkun. The advanced PID control and MATLAB simulation [M]. Beijing: electronic industry press, 2003.

[9] Xiao Jian. Design integrated with modern control system [M]. Beijing: China railway publishing house, 2000 .

[10] Cai Chunbo. PID parameter self-tuning algorithm and its application [D] Harbin: Harbin Institute of Technology,2005.

[11] Fang Kangling. Process control system [M]. Wuhan: Wuhan University Press,2002.

[12] Wang Danli, Zhao Yan .Matlab control system design and simulation application [M] Beijing: China Electric Power Press, 2007.

[13] Lou Shuntian, Hu Changhua. Based on the Matlab system analysis and design: fuzzy system [M]. $\mathrm{Xi}$ 'an: $\mathrm{xi}$ 'an university of electronic science and technology press, 2001.

[14] Wang Zheng lin, Guo Yangkuan.Process control and Simulink application [M] Beijing: Electronic Industry Press, 2006. 